E3S Web of Conferences 2, 03003 (2014)

DOI: $10.1051 /$ e3sconf/ 20140203003

(C) Owned by the authors, published by EDP Sciences, 2014

\title{
Sustainable transport systems: trends on needs, constraints, solutions
}

\author{
B. Dalla Chiara, I. Pinna*
}

POLITECNICO DI TORINO, Dept. DIATI, Transport Engineering, Corso Duca degli Abruzzi, 2410129 Torino, Italy

\begin{abstract}
In this historical moment, technology can guarantee transport systems some good solutions which seems to be quite in line with actual needs, by improving efficiency of engines (ICEs) or of travels or even rationalizing the consumption of related activities by using ITS (Intelligent Transport Systems) and by developing systems which can be sustainable through their whole life-cycle (LCC). Main results of the paper can be synthesised in pursuing the independence from the main source transport systems are based on, which is a nearly-monopoly, and use of lower unitary energy in motorised mobility in order to reduce the fuel consumption per person or per ton and - consequently - the emissions. This aim can be pursued either through higher capacity transport modes (e.g. trains, metros and automated people movers), yet guaranteeing as far as possible vehicles loaded more than their break-even in energy, or with a low level of black-oil energy used for vehicles: e.g., FEV, PHEV, natural gas for heavy-duty vehicles. The WTW analysis synthesises most of this idea.
\end{abstract}

Keywords: transport systems; energy use; sustainable motorised mobility; well-to-wheel analysis; new technologies and ITS.

\section{Introduction}

World is continuously evolving and in transport systems, as in other fields of human activities, needs and related innovations follow the times. For example, some milestones of innovations are - in centuries - the wheel, the coach with horses, trains ('800), cars (end of '800 and '900), metros (first half of the '900), high-speed trains ( $2^{\text {nd }}$ half of '900), automated metros and people movers (last 3-4 decades), intelligent transport systems (last 2-3 decades). Usually transport systems are conserved and updated, yet in history they become sometimes out of fashion and substituted by new means: the crisis of a field leaves the space to new inventions. We shall try to understand which kind of needs the present and future transport systems should satisfy, avoiding a defensive and passive conservation of the existing habits, unless still useful, and revitalising any possible inertial behaviour, which is typically aimed at conserving a gained result or an established economy.

\footnotetext{
* Corresponding author. Politecnico di Torino. Tel.: +39011090; fax +39011090 .

E-mail address: bruno.dallachiara@polito.it (B. Dalla Chiara).
} 


\section{Recent trends in individual mobility}

Analysing the recent evolutions of individual mobility in Europe and USA, they show a nearly consistent trend (Fig 1, Fig. 2).

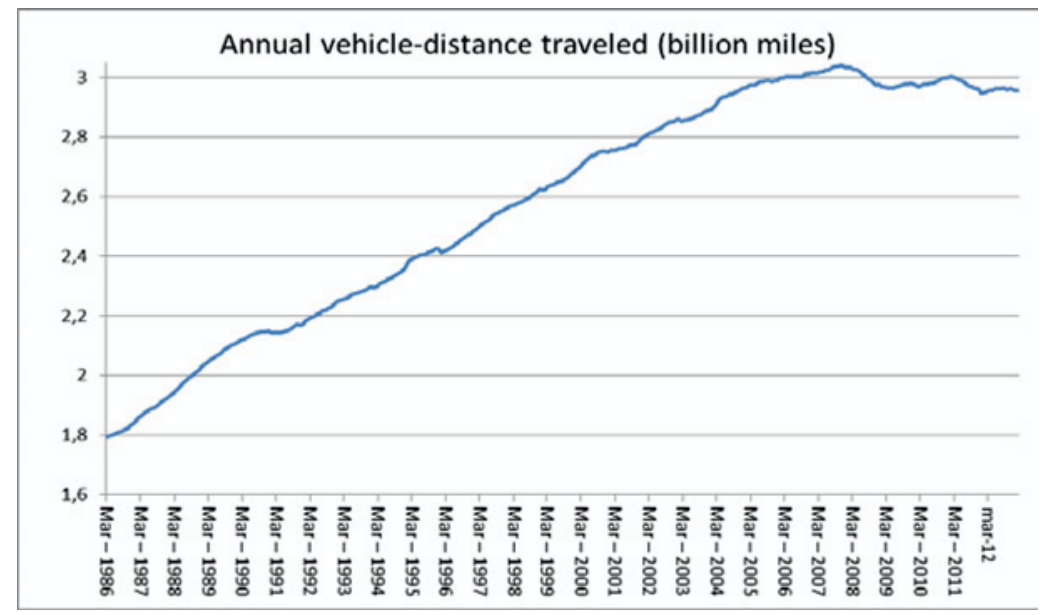

Figure 1. Annual vehicles distance covered on highways in USA, Moving 12-month total on all highways [1]

As a mere example, along the Italian toll motorways (Fig. 2), the light vehicles reduced their total distance coverage, in 2011, by $1.6 \%$ versus 2010; as regards heavy-duty vehicles, the veh $\cdot \mathrm{km}$ were nearly equal to those of $2010(-0,1 \%)$ and the traffic of heavy-duty vehicles in 2011 was less than the one recorded in 2003. While in France, on toll motorways, the comparison between 2007 through 2012 shows $-23.5 \% \mathrm{t} \cdot \mathrm{km}[2]$.

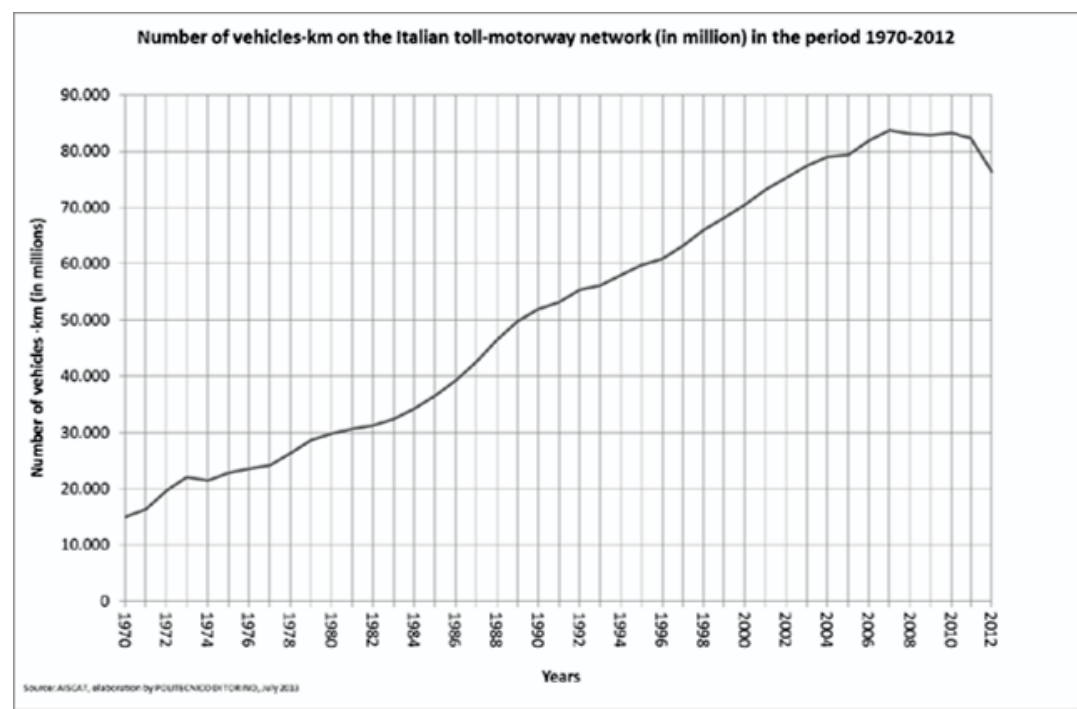

Figure 2. Vehicles per kilometres by all vehicles, 1970-2012, on the Italian toll-motorway network [3]. 
Looking in particular at the last decade, indicatively, the growth of circulating vehicles, infrastructures and motorised personal mobility - which has significantly marked the second half of the last century of USA, Japan and Europe - shows some conditionings or constraints, based on what is nowadays called "sustainable transport" or "sustainable motorised mobility". These elements can be summarized as follows:

A. The saturation of the land, meant as infrastructures on the territory and as vehicles on the infrastructures; deep awareness of such issue already emerged in the nineteen nineties with the spreading of the environmental impact assessment;

B. The raising concerns on the forthcoming limitedness of the energy resource - of black oil in particular, at least at widely accessible prices - on which transport depends for at least $96 \%$ in the European countries;

C. The release of gases and materials derived from combustion into the environment - implicitly a consequence of the energy use - with the subsequent atmosphere pollution and health issues, and the relevant commitments which have been taken worldwide;

D. The need to maintain and technologically update the existing infrastructures, meant as their economic sustainability in their whole life cycle cost; the State property increases with the development of new infrastructures as well as upgrading the existing network; overlooking an infrastructure may imply its loss of attractiveness;

E. The increase of safe mobility, which is a binding objective dictated by the EU as well as USA and Japan on land transport and which - since it has been established as a reduction of road accidents in particular, in absolute terms and not of rate - results to be incompliant with the growth of motorised mobility;

F. A natural limit in the continuous increase of long-range relationships among people, a possibly ethic objective; local relationships, both with one owns' family and for the regular development of on-site working activities, may become incompliant with the continuous growth of motorised mobility. This increase in mobility was welcome in the past.

\section{Trends on needs concerning energy use}

All the aforementioned constraints or conditioning to sustainable transport call for appropriate analysis. Transport systems are mainly characterized by vehicles which use distributed energy, with the exception - in general terms - of those systems which operate on fixed installations such as railways, subways, cableways and automated people movers [4]. As it will be specified further on, in the largest majority of cases the combustion of the energy source is developed directly by engines onboard the vehicles - be they on road, sea, inland waterways or air - provided with a fuel tank.

Almost all these transport systems are based upon oil-derived fuels, and the current alternatives often show significant limits. Transport systems operating on fixed installations do not strictly depend on these fuels since they use, with the exception of Diesel traction, electric lines supplied by power stations, irrespective on the energy source used to supply such stations. Moreover, transport field is the only one to be almost exclusively based upon a sole primary source [5]. The data supplied by the Italian Ministry of the Economic Development in 2010 lead to estimate that this dependence for Italy was nearly $93.4 \%$ for its use in transport system (road, rail, ...), though it seems to be reducing versus 2005 , when black oil was used for nearly $97 \%$. In 2011, for example, this value accounted for $98.2 \%$ in Great Britain ${ }^{1}$ and for $98.5 \%$ in Switzerland ${ }^{2}$, while in 2002 in Australia ${ }^{3}$ was worth of 99\%. Some figures, at European level, dated to the beginning of the decade [6] estimated this value at $98 \%$, while 
in the same year in USA it was $96 \%$, then reduced to $93.2 \%$ in 2010 [7]. The White book on Transport Systems of 2011 reports a figure of $96 \%$ in EU.

According to Eurostat, the impact in Europe (EU-25) of the transport systems in the overall energy consumption in 2004 resulted to be equal to $30.7 \%$. Such value has grown to approx. $32 \%$ (2006) to $33-34 \%$ (2008) in the following years $[8,9]$. The impact of the transport systems in Europe is nearly $10 \%$ greater than the world average (estimate: $20.42 \%$ in 2003 ), on the grounds of a larger motorised average mobility than in other continents. However Europe shows variability in the impact of transport consumption versus the overall final values reported for the different countries [10].

According to publications referred to $\operatorname{EU} 25[11,12,13,14]$, within the framework of motor transport systems, road haulage covers a share on the overall energy consumption (equivalent tons of oil ) of approximately $82.5 \%$, and is therefore predominant - at continental scale - over other modalities [15]; i.e. railways are estimated below 3\% approximately.

The impact of energy consumption in road transport is extremely variable also because of the different kinds of vehicles (from 2 up to 10 and more wheels). For example, we can mention - in 2008 - an exceptional impact of energy consumption on the running cost of freight equal to approximately 25 to $35 \%$, with further peaks up to $37 \%$ in 2011 (Italy). The incidence of freight transport by road including industrial and commercial vehicles - on the overall road transport energy consumption was approximately $39.5 \%$ in 2008 .

However, whereas the scenario of the circulating fleet - which is obviously not the sole factor affecting energy consumption - shows a trend to saturation in the European countries, the worldwide status is rather different, with a continuous growth.

If we observe the impact on the operational cost of energy consumption in railways, subways and tramways, the average consumption is $\sim 4-6 \%$; indicatively, for the Italian railways, some rail systems and subways, raise up to $\sim 6 \%$ on the budget in the case of traction for some automated undergrounds. Indeed metros present more frequent acceleration and braking phases which lead to a greater impact of energy consumption versus the case of medium to long distance traction, as the case of a national railway service.

The European Union appears to be well determined on tackling the energy issues in transport sustainability. Its White Paper "Roadmap to a Single European Transport Area - Towards a competitive and resource efficient transport system" [16] targets ambitious objectives concerning independence from black oil as well as the utilization of technologies in such pursuit, in line with "Horizon 2020". Also USA have recently made significant steps (April 2013) towards the independence from black oil for the traction and propulsion of transport systems.

\section{Constraints concerning energy in transport systems and possible migrations}

However, in order to provide an appropriate analysis on energy consumption within the context of its sustainability, and to trace an appropriate technological perspective related to all the transport 
systems, the well-to-wheel (WTW) index - a tool which was firstly proposed and consolidated in the automotive industry, but which is rarely applied to the other mode - needs to be applied.

WTW is an absolute energy index, whose function enables to compare combinations of different propulsion technologies and different fuels or energy carriers (i.e. hydrogen and electricity, which once they are produced - can be considered as fuels), obtained from various primary sources.

The WTW index, which can be defined as the integration of all the processes required to produce and distribute fuel - starting from its primary energy source - and use it in a vehicle [17], is composed of two more specific sub-indexes: well-to-tank (WTT) and tank-to-wheel (TTW).

WTT considers the amount of energy required to make the fuel available from the primary energy source - energy expenditure for extraction, for the chemical processes of transformation and for transport - up to the supply into the car tank, in a broad meaning. It is usually expressed in $\mathrm{MJ}_{\mathrm{t}} / \mathrm{MJ}_{\mathrm{f}}$, where $\mathrm{MJ}_{\mathrm{t}}$ is the overall amount of energy spent to make available such $\mathrm{MJ}$ of fuel and $\mathrm{MJ}_{\mathrm{f}}$ is the energy contained in the fuel stored in the vehicle tank.

On the other hand, TTW considers the amount of energy used to move a means of transport along a given distance, which depends on the combination of the fuel and of the propulsive technology used.

On the analysis point of view, the assessment of the WTW index is provided by:

$$
W T W\left[\frac{M J_{t}}{k m}\right]=W T T\left[\frac{M J_{t}}{M J_{f}}\right] \cdot \operatorname{TTW}\left[\frac{M J_{f}}{k m}\right]
$$

In the automotive industry, TTW can be determined through standardized guiding processes, where the speeds and the driving conditions (i.e. stops at the traffic lights and slopes) are as close to reality as possible.

It must be set forth that calculating WTW for the rail transport- instead - is a complex exercise, mainly because of the little experience in the sector.

An important consideration has to be highlighted: the WTW analysis becomes necessary when we want to migrate from a transport market which is nearly fully dominated by black oil - through the products of its distillation - as the primary energy source to a scattered or differentiated one. Any alternative has to be evaluated on the basis of the energy needed to obtain it - especially in case it was not directly used, i.e. burnt, inside the vehicle as it occurs with fuels - with particular reference to the energy carriers (Fig.3).

Energy supply for transport could take a large number of different pathways as shown in Fig.3, alternative fuels will gradually become a much more significant part of the energy mix. It is nevertheless difficult to identify a single candidate: the fuel demand and the challenges set by the greenhouse gases will most likely imply the use of a wide variety of primary energies. There is rather broad agreement that all the sustainable fuels will be needed to solve the expected supply/demand tensions. 


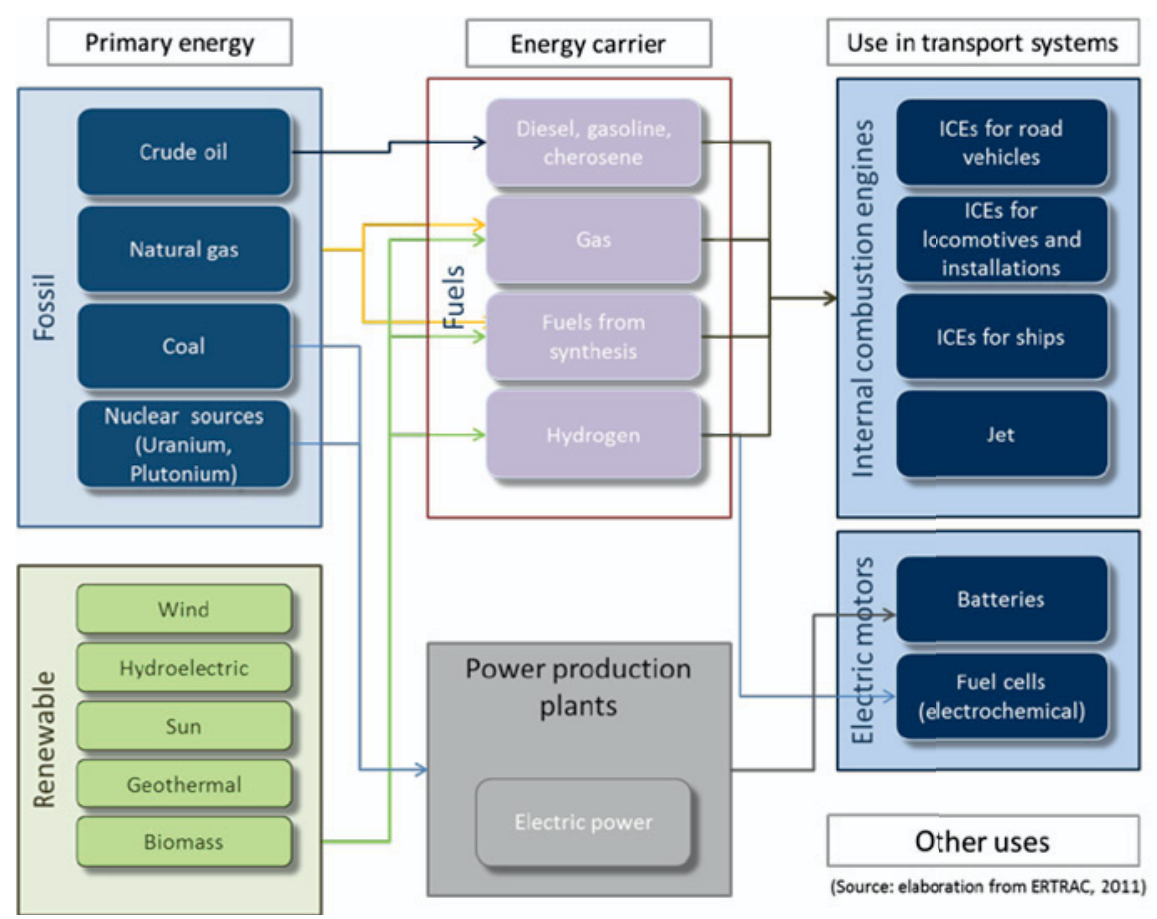

Figure 3. Energy pathways in transport and other sectors (Source: modifications from a basis by ERTRAC).

Irrespectively on the costs or prices of the energy source, which are subject to variations due to the market, the WTW index varies in time and space, since it is related to the actual or known availability of sources and to the kind of energy in use within a given country, region or area (e.g. agricultural uses).

\section{Role of full cargo and high occupancy}

A merely quantitative analysis would not be sufficient for the aim of analysing sustainability, but the actual use of every transport mode should be taken into consideration as well. On this point of view, public transport is obviously favoured - especially rail, cableways and underground systems because of their independence from black oil. However, occupancy is a relevant factor as well. The graphs reported in Fig. 4 represents the energy consumed on board per person-kilometre, based on the calculation of energy dissipation given to aerodynamic, specific resistance on a straight and plan path. 


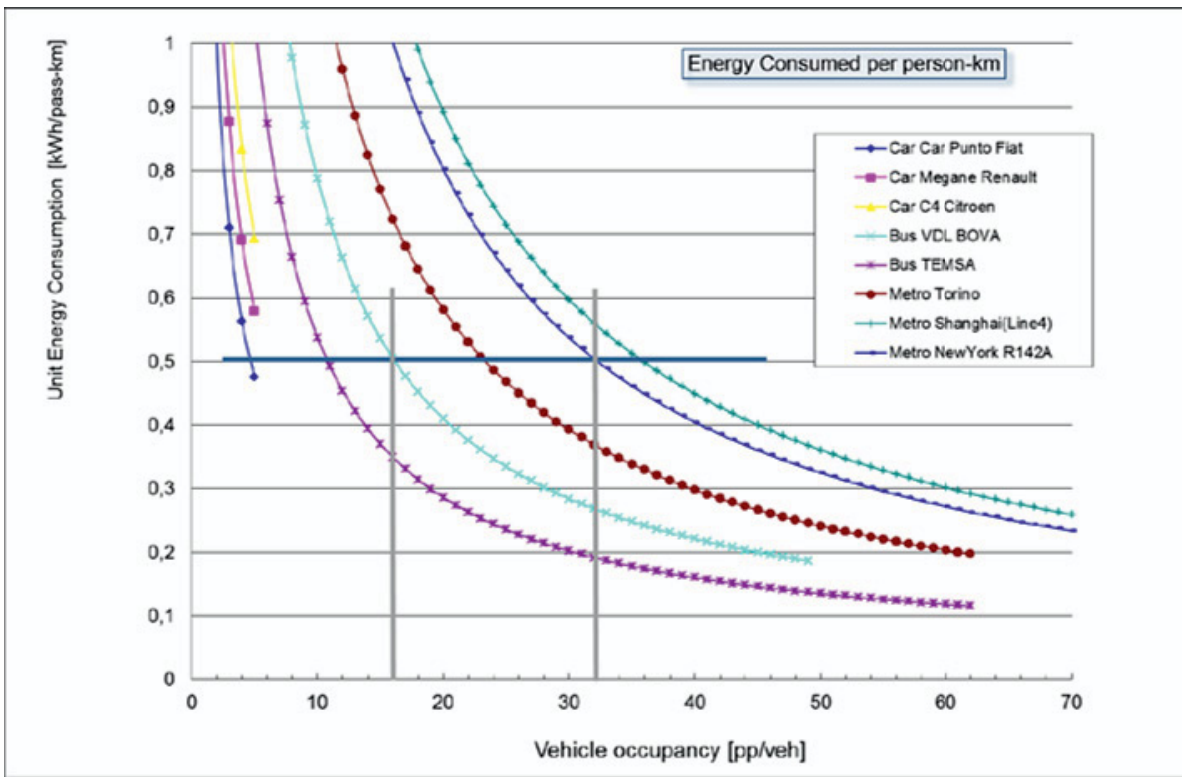

Figure 4. Energy consumed per person-km.

\section{Possible solutions}

What has arisen from the previous remarks implies that, in Europe, we should not necessarily expect an increase in either mobility or in the consumption related to it, whilst safety, quality and efficiency - mainly as far as energy is concerned - are to be pursued [18].

Subsequently, our economic system, i.e. the one of the European countries, seems to be evolving from a context prevailingly based on production - which is both industrial and civil, the latter is meant specifically as building of transport infrastructures - to another one more based upon maintenance, beside efficiency, quality and safety.

However, on the grounds of the world scenario, one of the main challenges our society is facing is the procurement and management of energy for transport fuels and carriers, as well as the consequences of their use on both people and the environment.

As regards the road vehicles, Fig. 5 reports a viable scenario for the future traction and propulsion, on the basis of the WTW analysis and all previous considerations, interaction of the production with the territory and energy availability[19].

Our analysis leads to argue that there would be no single solution that could be used on all transport modes; a viable energy carrier for this purpose, such as biofuels, cannot be sustainably produced in the quantities required. Biofuels could therefore be used selectively for transport modes where electric vehicles and fuel cells are not expected to be technically viable. For passenger cars and LDVs, the development of Hybrid electric vehicles (HEV), battery and fuel cell vehicles can be pursued, keeping in mind the different upfront costs of these two technologies. 


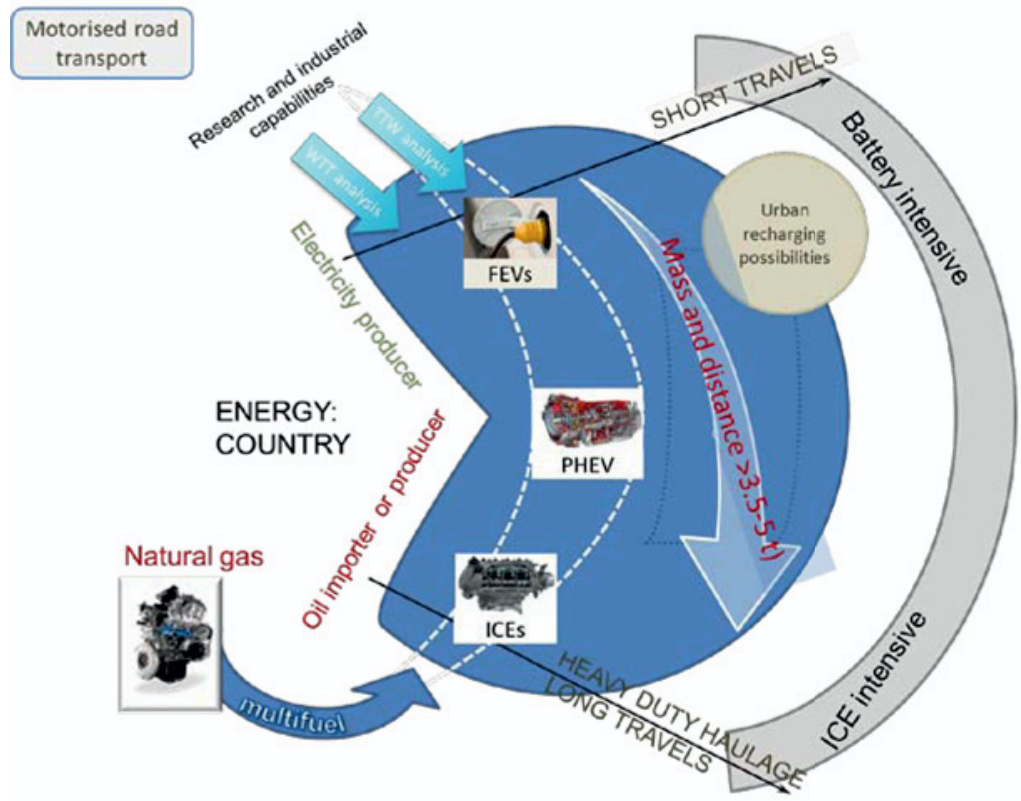

Figure 5. A perspective on road vehicle traction and propulsion on the basis of WTW analysis, interaction of the production with the territory and energy availability (Politecnico di Torino, 2013).

The viability of large-scale market penetration of both battery and fuel cell vehicles greatly depends on the forthcoming developments of the basic technology they both require. Literature sources claim that such technologies may achieve sufficient development to start penetrating the market within the next 10 to 15 years. If only one of the two technologies reaches the development required to penetrate the market of light-duty vehicles (i.e. covering all possible distance and weight segments of LDVs), refuelling/recharging infrastructures would need to be built at the same time of or shortly before any large scale penetration, and then this technology would dominate the market and might replace oil-based fuels for urban transport.

The development of mentioned technologies would highly depend on research and development as well as on the implementation of infrastructures, which should rely on public resources and investments at least to a certain extent.

Therefore, the problem might be to partially reverse to the electric grid the energy used by a sector which weights for nearly one third of the overall energy consumption in Europe and which aims to exit from the monopoly of that source. In order to solve this, various solutions may arise in the forthcoming future: from higher efficiency internal-combustion-engines (ICEs) to the rechargeable hybrid-electric (PHEV), and the full-electric (FEV) vehicles (charged on the grid, with a quote likely variable from Nation to Nation and from Region to Region), to a higher load on public transport based on electric power (provided that it is well used), to alternative primary energies, including Natural Gas. 


\section{Conclusions}

In this historical moment, technology is offered as a crosswise solution to the energy issue, and as a tool through which Man can remedy the fact that the resource which is prevailingly being utilized in transport may become scarce or be perceived as such. This can be obtained by improving efficiency of engines or of travels or even rationalizing the consumption of related activities by using ITS (Intelligent Transport Systems) and by developing a structures which can be sustainable through a limited supply of fossil fuels [20,21].

Main results can be synthesised in the sentence: pursuing the independence from the main source, which is nearly a monopoly, and use of lower unitary energy in motorized mobility in order to reduce the fuel consumption per person or per ton and - consequently - the emissions. This aim can be pursued either through higher capacity transport modes, yet guaranteeing as far as possible vehicles loaded more than their break-even in energy, or with a low level of energy used for vehicles. The WTW analysis synthesizes, in effect, most of this idea [22, 23].

A conclusive message could then be that the improvement of what exists can be pursued in terms of quality, safety and efficiency of both engines and transport systems, also through the support of telematics and "ITS": the path is the one of both efficiency and alternative energies. In this perspective, when well used, the public transport systems result therefore to offer a good and even optimum solution - wherever it is possible to meet both mobility and freight haulage requirements because of their own constitution.

The assignment of space to road transport could, at first, take into account the energy used by transport modes, possibly with a WTW analysis at the base, and any analysis on new infrastructures should include not only the coverage of the relevant investment but also the capability to maintain and equip such infrastructures with modern technologies (ITS). The scarce resources are nowadays: space, mostly in cities, and energy, and this should constitute the constraints to be taken into account in any choice concerning any high-level planning of transport system [22, 23, 24].

\section{References}

[1]. US Department of Transportation, Federal Highways Administration, Travel Monitoring and Traffic Volume, (January 2013)

[2]. FNTR (Fédération Nationale des Transports Routier), Traffic data (2013)

[3]. AISCAT, Informazioni (Data book) (1970-2013)

[4]. Dalla Chiara, B., Degioanni, P., Fumarola, FP., Riepilogo di sistemi di trasporto innovativi. Ingegneria Ferroviaria. LXIII(1) (2008a).

[5]. Dalla Chiara, B., Ricagno, R., Santarelli, M., Sostenibilità energetica dei trasporti: analisi dei consumi e della soluzione ferroviaria. Ingegneria Ferroviaria, LXIII(6), 531-543, (2008b)

[6]. Commission of the European Communities, 2001. A Sustainable Europe for a Better World: A European Union Strategy for Sustainable Development, Brussels, 15 May.

[7]. US Transportation, Energy Data Book 2011, Ed30 (2011)

[8]. Dalla Chiara, B.. Considerations on the demand and use of energy in the transport systems / Considerazioni sulla domanda ed impiego di energia nei sistemi di trasporto. Ingegneria Ferroviaria LXV(7-8), July-August, 673-685 (2010).

[9]. Energy Information Administration - EIA. International Energy Outlook (June 2006).

[10].Unione Petrolifera, "Data book", Energia e Petrolio (2008-2009-2011-2013)

[11].European Commission, The annual energy and transport review for 2004 (December 2005).

[12].European Commission, Energy and Transport in Figures 200, (2005) 
[13].European Commission, European Energy and Transport: scenarios on energy efficiency and renewables (2006).

[14].European Commission. European Energy and Transport: scenarios on high oil and gas prices (2006).

[15].European Commission, Eurostat, G. Campbell, Panorama of Transport, Luxembourg (2007).

[16].EU, WHITE PAPER Roadmap to a Single European Transport Area - Towards a competitive and resource efficient transport system, COM/2011/144, CE, 28.3.2011 (2011)

[17].European Commission, Well-to-Wheel analysis of future fuels and powertrains in the European context: WELL-to-WHEEL, Version 1b, (March 2007, previous edition in 2004).

[18].Deflorio, F., Dalla Chiara, B., Barosso, M.. Controllo accessi in aree urbane: comparazione di strategie basate su sistemi telematici (ITS) mediante modelli di micro-simulazione del traffico. Scientific Seminar on Interventi e metodologie di progetto per una mobilità sostenibile, pp. 189-203 (2008).

[19].European Expert Group on Future Transport Fuel, Alternative Fuels (December 2011)

[20].Dalla Chiara, B., Pinna, I., 2012. Sustainable development of automotive industry On issues of sustainable transport. Proceedings of the International congress on Motor vehicles and Motors 2012, Kragujevac, $3^{\text {rd }}-5^{\text {th }}$ October (2012).

[21].Kanninen B. J., Intelligent transportation systems: An economic and environmental policy assessment, Transportation Research Part A: Policy and Practice, Volume 30, Issue 1, January 1996, Pages 1-10, ISSN 0965-8564 (1996)

[22].Pant, K., Pinna I., Dalla Chiara B., Bensaid, S.. Transport and energy in India. Energy used by Indian transport systems and consequent emissions: the need for quantitative analyses (Well-to-Wheel, Lifecycle). p. 1-51, EBTC Report. (2013)

[23].Pinna, I., Dalla Chiara, B., Pant, K., Energy used by transport systems in India: role of urban population, sources, alternative modes and quantitative analyses. Proceedings of the Nineteenth International Conference on Urban Transport and the Environment, Kos, Greece, $29^{\text {th }}-31^{\text {st }}$ May (2013)

[24].Dalla Chiara B., Pellicelli M., Pinna I., Sustainable land transport systems from the energy viewpoint: technological perspectives and industrial choices, Transportation (to be published) 